\title{
Comparing Ipsilateral and Contralateral Laminotomy with Bilateral Decompression in Cases with Far Lateral Disk Herniation and Lumbar Spinal Stenosis
}

\author{
Ezgi Akar ${ }^{1, \odot ~ A h m e t ~ O ̈ g ̆ r e n c i ², \odot ~ O r k u n ~ K o b a n ², \odot ~}$ \\ ${ }^{1}$ Department of Neurosurgery, Haydarpasa Numune Training and \\ Research Hospital, Istanbul, Turkey \\ 2Department of Neurosurgery, Okan University, Istanbul, Turkey \\ ${ }^{3}$ Department of Neurosurgery, Neurospinal Academia, Istanbul, \\ Turkey
}

\author{
Mesut Yılmaz ${ }^{3, \odot}$ Sedat Dalbayrak ${ }^{2, \odot}$
}

Indian J Neurosurg 2021;10:121-127.

\author{
Address for correspondence Ezgi Akar, MD, Haydarpasa \\ Numune Training and Research Hospital, Department of \\ Neurosurgery, Tibbiye Street, Uskudar, Istanbul 34668, Turkey \\ (e-mail: ezgiaycicek@gmail.com).
}

\begin{abstract}
Keywords

- spinal stenosis

- far lateral disk herniation

- unilateral approach

- contralateral

- pars interarticularis

Introduction The aim of this study was to compare clinical results of bilateral decompression and laminotomy and contralateral laminotomy following discectomy from the same side in patients who have far lateral disk herniation and lumbar spinal stenosis at the same level.

Materials and Methods Twenty-four patients with far lateral disk herniation have been divided into two groups: group $1(n=14)$, those who have been through bilateral canal decompression with far lateral discectomy and ipsilateral approach, and group 2 $(n=10)$, those who have been through far lateral discectomy and bilateral decompression with unilateral approach from contralateral side. Early postoperative, 1 st month, and 12th month back and leg pain Visual Analogue Scale (VAS) scores of the patients have been retrospectively evaluated.

Results There is no significant difference between 1st month back and leg pain VAS scores of the groups. But 12th month back and leg pain VAS scores of group 1 are significantly higher than 1st month VAS scores. Also, 12th month back and leg pain VAS scores of group 1 are significantly higher than group 1 . In the scanning carried out when the complaints of eight patients in group 1 continued, pars interarticularis fracture has been observed on the side where the surgery has been performed (57.1\%). Six of these eight patients have been through stabilization surgery (42.8\%).

Conclusion Long-term postoperative results are better in cases who have been performed bilateral decompression with unilateral approach from contralateral side with median incision following paramedian incision discectomy in patients with far lateral disk herniation and spinal stenosis.
\end{abstract}

\section{Introduction}

The term far lateral or extreme lateral disk herniation is used for cases in which fragment is lateral to extraforaminal, pedicle level and sublateral of facet joint. ${ }^{1}$ Various surgical techniques have been used to treat far lateral disk herniation.
Lateral approach, which is performed between transverse processes splitting intertransverse ligament and the muscle, is the surgical method that is used today. ${ }^{2}$ For lateral approach, traditional median incision or paramedian "Wiltse approach" can be used. ${ }^{3}$ We have used both techniques in our cases. published online July 15,2021
DOI https://doi.org/ 10.1055/s-0041-1726604 ISSN 2277-954X (c) 2021. Neurological Surgeons' Society of India.

This is an open access article published by Thieme under the terms of the Creative Commons Attribution-NonDerivative-NonCommercial-License, permitting copying and reproduction so long as the original work is given appropriate credit. Contents may not be used for commercial purposes, or adapted, remixed, transformed or built upon. (https://creativecommons.org/licenses/by-nc-nd/4.0/). Thieme Medical and Scientific Publishers Pvt. Ltd. A-12, 2nd Floor, Sector 2, Noida-201301 UP, India 
In the treatment of spinal stenosis, partial laminectomy, total laminectomy, spinal instrumentation, and bilateral spinal decompression with unilateral approach can be used. ${ }^{4}$ Bilateral decompression with unilateral approach is a minimal invasive method, as an alternative to classical laminectomy, and the decrease in postoperative instability risk is the advantage of this approach. ${ }^{5}$

In our study, we have compared two different surgical methods where we have applied bilateral decompression with unilateral approach for spinal stenosis following removal of far lateral disk fragment. We have defined two different openings: in some cases, we have applied unilateral spinal canal decompression from the side of disk herniation while in some cases, we have applied bilateral decompression with unilateral approach across disk herniation, and we have clinically evaluated the postoperative results.

In our knowledge, there is no surgical technique defined for cases with far lateral disk herniation and spinal stenosis at the same level.

\section{Materials and Methods}

We have retrospectively evaluated the results of 24 patients with lumbar spinal stenosis and far lateral disk herniation, and we have operated with two different methods. In the patients having magnetic resonance imaging (MRI) scans, there has been spinal stenosis with/without lateral recess syndrome at L4-5 level and far lateral lumbar disk herniation at the same level and all patients have been treated with one level surgery. Patient inclusion criteria of our study are: (1) no history of spinal surgery, (2) one level spinal stenosis at L4-5 level, (3) unilateral far lateral disk herniation at L4-5 level, (4) previous bilateral radicular symptoms of patients whose complaints increased due to far lateral disk herniation, and (5) no axial back pain to support instability in the preoperative scanning. Patients have been divided into two groups based on the surgical method applied.

\section{Surgical Procedure}

In the first group (14 patients), lateral aspect of facet joint and intertransverse interval have been reached through wide median skin incision. L4 and L5 transverse processes, lateral aspect of the pars interarticularis, inferior articular facet, superior articular facet, and facet joint line have been determined. Lateral aspect of pars interarticularis and facet joint face have been trimmed and far lateral discectomy has been applied. And then partial hemilaminectomy, flavectomy, and foraminotomy have been applied on the same side. After this procedure, operation table has been tilted to the opposite side; flavectomy and foraminotomy have been applied under the spinous process (-Fig. 1). In the second group (10 patients), two different skin incisions have been used. With paramedian skin incision, pars interarticularis lateral and facet joint lateral face have been trimmed and far lateral discectomy applied. After that, we have entered with median skin incision, on the opposite side of far lateral disk herniation, and carried out unilateral partial hemilaminectomy, flavectomy, foraminal decompression, and opposite side flavectomy, as well as foraminotomy.

Preoperative, postoperative 1st month, and postoperative 12th month Visual Analogue Scale (VAS) scores have been recorded in all patients. Then 1 st and 12 th month VAS scores of each group have been compared both within the same group and between the groups. Imaging studies (MRI, computed

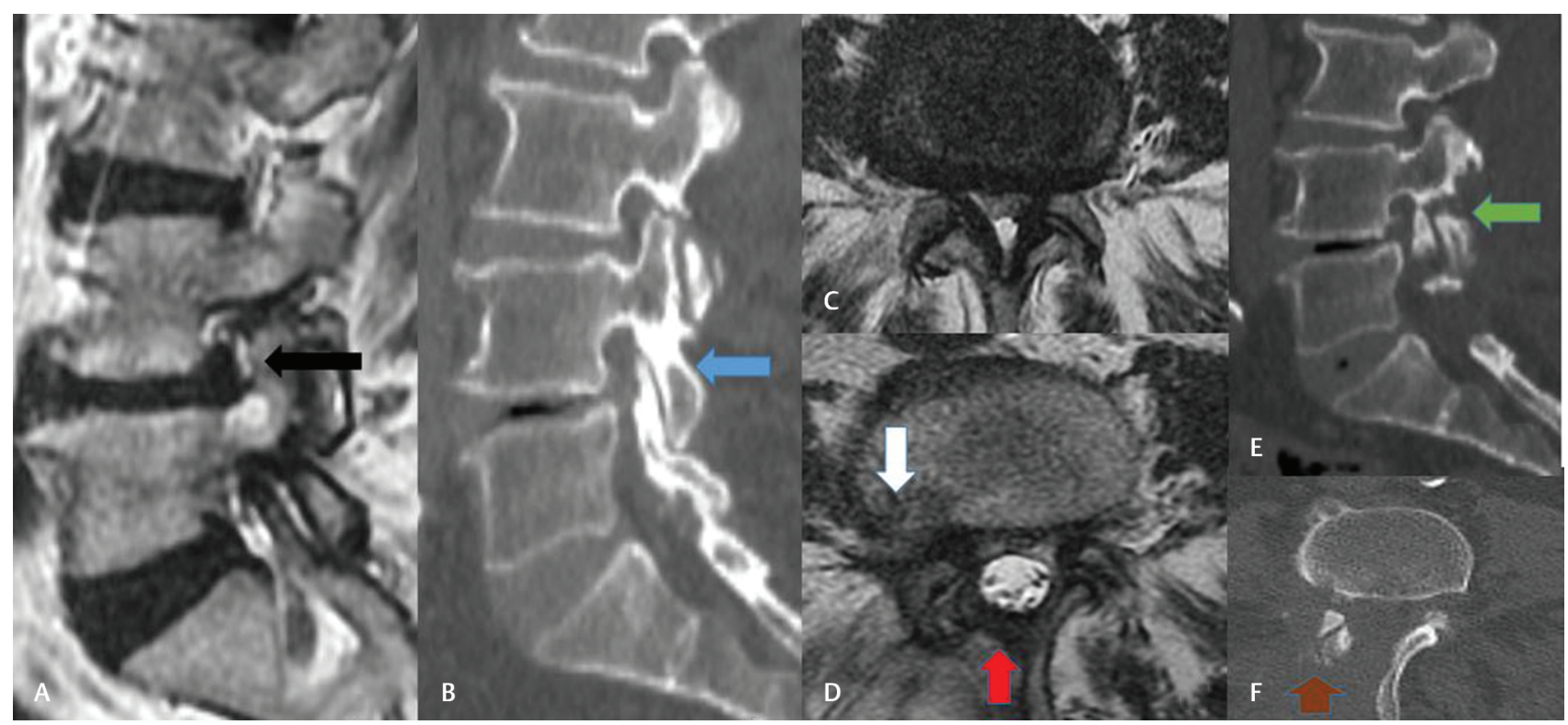

Fig. 1 (A) Preoperative sagittal magnetic resonance imaging. Extraforaminal disk herniation compressed the nerve root (black arrow). (B) Sagittal computed tomography (CT) image shows that the pars interarticularis is intact (blue arrow). (C) L4-5 section shows spinal stenosis in the section taken at recess level. (D) In postoperative axial section, it is seen that the same level is increased by decompression from the right side of the canal (red arrow), and decompression is performed in the extraforaminal area (white arrow). (E) In the postoperative period in the sagittal section, the pars is seen broken (green arrow). (F) In postoperative axial CT, both intracanal and extracanal bone structures after decompression are seen (orange arrow). 
tomography, dynamic X-rays) have been carried out for patients whose pains increased in back and/or leg in postoperative 12th month controls.

\section{Statistical Analysis}

For statistical analysis, NCSS-Number Cruncher Statistical System-2007 (Kaysville, Utah, United States) program was used. During the evaluation of study data, descriptive statistical methods (mean, standard deviation, median, frequency, ratio, minimum, maximum) were applied. Qualitative data normal distribution longitudes were examined by Kolmogorov-Smirnov test, Shapiro-Wilk test, and graphical assessments. In the comparisons of normal distribution exhibiting three and over three groups one-way analysis of variance test and in bilateral comparisons Bonferroni test were implemented. Significance at least evaluated on $p<0.05$ level.

\section{Results}

There were total 24 patients; in group 1 there were 14 patients out of which 6 were males and 8 females, and the average age was 52.4. In group 2, there were 10 patients out of which 6 were males and 4 females, and the average age was 54.6. Average follow-up period of the cases was 12.4 months. In both groups, averages of preoperative and postoperative 1st month and 12th month VAS scores were determined separately. Preoperative average leg VAS score of group 1 was $6.07 \pm$ 1.32 , while back VAS score was $4.43 \pm 1.02$; preoperative average leg VAS score of group 2 was $7.1 \pm 1.5$, while back VAS score was $3.3 \pm 0.95$. Postoperative average leg VAS score of group 1 in the 1 st month was $1.64 \pm 0.63$ while postoperative average VAS score of group 1 in the 12th month was
$3.57 \pm 1.16$. Postoperative average VAS score of group 2 in the $1 \mathrm{st}$ month was $1.6 \pm 0.7$ while postoperative average VAS score of group 2 in the 12 th month was $1.4 \pm 0.7$. There was a significant difference between the preoperative and postoperative 1st month VAS scores of group 1 and group 2 (-Tables 1-3). According to the VAS scores, the patients in all groups improved after surgery. When the postoperative back pain and leg pain VAS score changes in group 1 were evaluated for the 1 st and 12th months, 12th month VAS scores were found to be significantly higher ( - Tables 1-3; - Figs. 2 and 3). When the postoperative back pain and leg pain VAS score changes in group 2 were evaluated for the 1 st and 12th months, it was observed that there was no significant difference between postoperative 1st and 12th month VAS scores (-Tables 1-3; - Figs. 2 and 4). When postoperative 1st and 12th month VAS scores of both groups were evaluated, no significant difference was observed between 1st month back pain and leg pain VAS scores. However, when postoperative 12th month VAS scores were compared, back and leg pain VAS scores of group 1 were found to be significantly higher (-Tables 1 and 2). When group 1 was evaluated within itself, in the scanning carried out due to increasing back and leg pain VAS scores in the 12th month, 8 of the 14 patients (57.1\%) were found to have pars interarticularis fracture and instability. Since six of these eight $(42.8 \%)$ patients did not have conservative treatment, they applied for stabilization surgery.

\section{Discussion}

Degenerative spinal stenosis is seen most frequently at L4-5 level. ${ }^{6-8}$ Since it is the distance where the narrow canal is observed more frequently and the surgical anatomic

Table 1 The frequencies of preoperative, postoperative 1st month, and postoperative 12th month leg VAS scores of both groups

\begin{tabular}{|c|c|c|c|c|c|c|c|}
\hline & & Preope & & Postop & st month & Postop & 2th month \\
\hline \multirow{9}{*}{$\begin{array}{l}\text { Group } 1 \\
\text { leg }\end{array}$} & Value & Count & Percent & Count & Percent & Count & Percent \\
\hline & 1 & 0 & 0 & 6 & 42.86 & 0 & 0 \\
\hline & 2 & 0 & 0 & 7 & 50.00 & 2 & 14.29 \\
\hline & 3 & 0 & 0 & 1 & 7.14 & 6 & 42.86 \\
\hline & 4 & 2 & 14.29 & 0 & 0 & 3 & 21.43 \\
\hline & 5 & 3 & 21.43 & 0 & 0 & 2 & 14.29 \\
\hline & 6 & 3 & 21.43 & 0 & 0 & 1 & 7.14 \\
\hline & 7 & 4 & 28.57 & 0 & 0 & 0 & 0 \\
\hline & 8 & 2 & 14.29 & 0 & 0 & 0 & 0 \\
\hline \multirow{8}{*}{$\begin{array}{l}\text { Group } 2 \\
\text { leg }\end{array}$} & 1 & 0 & 0 & 5 & 50.00 & 6 & 42.86 \\
\hline & 2 & 0 & 0 & 4 & 40.00 & 7 & 50 \\
\hline & 3 & 0 & 0 & 1 & 10.00 & 1 & 7.14 \\
\hline & 4 & 0 & 0 & 0 & 0 & 0 & 0 \\
\hline & 5 & 4 & 40 & 0 & 0 & 0 & 0 \\
\hline & 6 & 2 & 20 & 0 & 0 & 0 & 0 \\
\hline & 7 & 3 & 30 & 0 & 0 & 0 & 0 \\
\hline & 8 & 1 & 10 & 0 & 0 & 0 & 0 \\
\hline
\end{tabular}


124 Far Lateral Disk Herniation with Lumbar Spinal Stenosis Akar et al.

Table 2 The frequencies of preoperative, postoperative 1st month, and postoperative 12th month back VAS scores of both groups

\begin{tabular}{|c|c|c|c|c|c|c|c|}
\hline & & Preope & & Postop & st month & Postop & 2th montl \\
\hline & Value & Count & Percent & Count & Percent & Count & Percent \\
\hline & 1 & 0 & 0 & 9 & 64.29 & 0 & 0 \\
\hline & 2 & 0 & 0 & 5 & 35.71 & 4 & 28.57 \\
\hline & 3 & 3 & 21.43 & 0 & 0 & 2 & 14.29 \\
\hline $\begin{array}{l}\text { Group } 1 \\
\text { back }\end{array}$ & 4 & 4 & 28.57 & 0 & 0 & 3 & 21.43 \\
\hline & 5 & 5 & 35.71 & 0 & 0 & 1 & 7.14 \\
\hline & 6 & 2 & 14.29 & 0 & 0 & 1 & 7.14 \\
\hline & 7 & 0 & 0 & 0 & 0 & 2 & 14.29 \\
\hline & 8 & 0 & 0 & 0 & 0 & 1 & 7.14 \\
\hline & 1 & 0 & 0 & 6 & 60 & 1 & 10 \\
\hline & 2 & 2 & 20 & 4 & 40 & 6 & 60 \\
\hline & 3 & 4 & 40 & 0 & 0 & 3 & 30 \\
\hline Group 2 & 4 & 3 & 30 & 0 & 0 & 0 & 0 \\
\hline back & 5 & 1 & 10 & 0 & 0 & 0 & 0 \\
\hline & 6 & 0 & 0 & 0 & 0 & 0 & 0 \\
\hline & 7 & 0 & 0 & 0 & 0 & 0 & 0 \\
\hline & 8 & 0 & 0 & 0 & 0 & 0 & 0 \\
\hline
\end{tabular}

Table 3 The statistical analysis of preoperative, postoperative 1st month, and postoperative 12th month VAS scores of both groups

\begin{tabular}{|l|l|l|l|l|l|l|l|l|l|}
\hline & \multicolumn{3}{|c|}{ Preoperative } & \multicolumn{3}{c|}{ Postoperative 1st month } & \multicolumn{3}{c|}{ Postoperative 12th month } \\
\hline $\begin{array}{l}\text { Group 1 } \\
\text { leg }\end{array}$ & Mean & Standard & Median & Mean & Standard & Median & Mean & Standard & Median \\
\cline { 2 - 11 } & 6.07 & 1.32 & 6 & 1.64 & 0.63 & 2 & 3.57 & 1.16 & 3 \\
\hline $\begin{array}{l}\text { Group 2 } \\
\text { leg }\end{array}$ & 7.1 & 1.5 & 7 & 1.6 & 0.7 & 1.5 & 1.4 & 0.7 & 1 \\
\hline $\begin{array}{l}\text { Group 1 } \\
\text { back }\end{array}$ & 4.43 & 1.02 & 4.5 & 1.35 & 0.5 & 1 & 4.21 & 2.08 & 4 \\
\hline $\begin{array}{l}\text { Group 2 } \\
\text { back }\end{array}$ & 3.3 & 0.95 & 3 & 1.4 & 0.52 & 1 & 2.2 & 0.63 & 2 \\
\hline
\end{tabular}
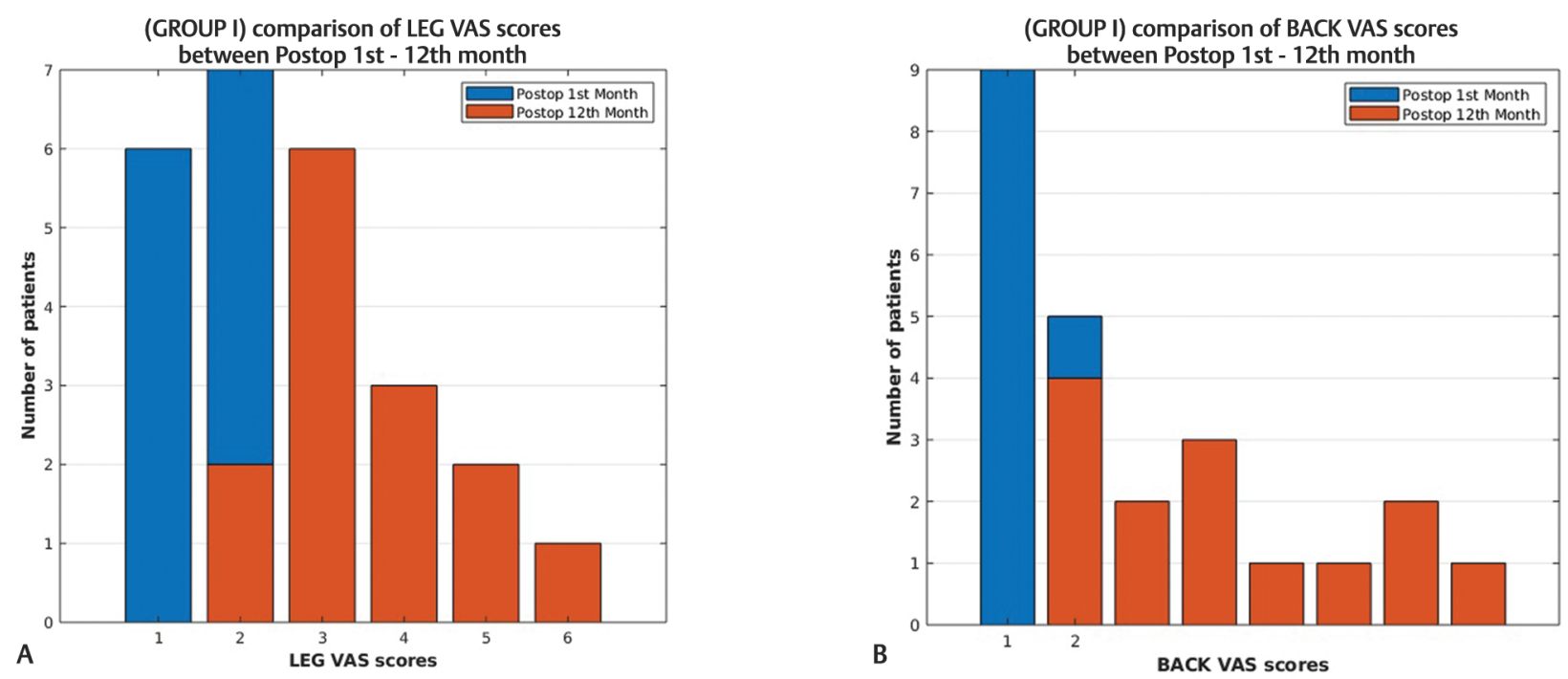

Fig. 2 (A) Comparison of leg Visual Analogue Scale (VAS) scores between postoperative 1st and 12th months for group 1. (B) Comparison of back VAS scores between postoperative 1st and 12th months for group 1 . 
factors are similar, we have included in our study the cases with pathology at L4-5 level. In spinal stenosis cases, surgical treatment is planned for patients where no response is obtained to conservative treatment and there is a progressive loss of strength. The aim of surgical treatment is to increase the diameter of effective spinal canal. Total laminectomy and total or partial facetectomy are traditional treatment methods of spinal stenosis. However, since postoperative instability can be observed, stabilization operation is frequently included in laminectomy procedures. ${ }^{9}$ With the progress of time, muscle-protective surgery has been discussed to decrease the postoperative back pain and minimal invasive surgical methods have been discussed as the importance of supraspinous and interspinous ligaments in stabilization of spine has become a current issue. ${ }^{10}$ Furthermore, there has been no correlation between the amount of increase in spinal canal diameter and amelioration of neurological symptoms. ${ }^{11}$ In this vein, laminotomy, medial facetectomy, and laminoplasty methods can be used. If radicular findings are bilateral, bilateral laminoforaminotomy can be applied. However, bilateral medial facetectomy raises the risk of instability and increases the risk of postoperative muscle atrophy and back pain. ${ }^{2}$ Hence, bilateral decompression is applied with unilateral approach in many centers for a long while. In surgical operations, anatomically, ipsilateral side lamina, ligamentum flavum, and medial side facet joint is trimmed; on the contralateral side, only ligamentum flavum and ventromedial side of facet joint can be removed. ${ }^{13}$ Bilateral decompression procedure with unilateral approach is carried out from the symptomatic side on patients with a complaint on a single side. However, in cases with facet joint osteoarthritis, it can be carried out from the side where the facet joint morphology is better. ${ }^{14,15}$

In patients with bilateral leg claudication findings, surgical operation is recommended from the more symptomatic side or from the side that does not have facet joint hypertrophy. However, there are no findings regarding surgical approach in spinal stenosis cases with far lateral disk herniation and bilateral leg claudication in the literature. While bilateral decompression with unilateral approach is a minimal invasive option in these cases, the side from which decompression will be applied has been discussed in this paper. Postoperative results have been evaluated in the group where far lateral discectomy with median skin incision and bilateral spinal canal decompression from the same side with unilateral approach has been applied, and in two groups where spinal canal decompression has been applied with median incision from the opposite side of the disk herniation.

Almost $7 \%$ of all disk herniations are far lateral and have mostly been observed at L4-5 level. ${ }^{2}$ Surgical treatment is needed for cases with neurological deficit without a regression in the pain despite the conservative treatment. There are several methods defined in surgery of far lateral disk herniation; these techniques are total or medial facetectomy, laminectomy, hemilaminectomy, access by pars interarticularis, and intertransverse muscle and ligament excision between upper and lower transverse processes. ${ }^{2,16}$ The most frequently used approach to protect facet joint is discectomy from lateral aspects of pars interarticularis using the intertransverse interval. In this vein, traditional median incision and paramedian Wiltse approaches can be used. ${ }^{3}$ By both incisions, after opening fascia, multifidus and longissimus muscles are dissected by subperiosteal dissection. Lateral aspect of pars interarticularis, superior and inferior transverse process, inferior and superior articular facet, and lamina is identified. Pars interarticularis lateral is trimmed and "safety zone" defined in lamina facet junction lateral is reached. Ligamentum flavum lateral part, which is called as "falciform ligament," adjacent to pars interarticularis lateral is found and opened by sharp knife or dissector to reach nerve root and disk fragment. In many cases, lateral part of pars interarticularis is trimmed with Kerrison rongeur or high speed drill; and the disk fragment whose nerve root has been relocated to posterior or superior is removed. ${ }^{17}$ Pars interarticularis is a weak structure and its contribution to stabilization of the spine is important; therefore, in order to prevent stress fractures of pars interarticularis and related complications, bone resection in this part must be kept limited..$^{18}$ Since lateral part of pars interarticularis will be resected in cases with far lateral disk herniation and spinal stenosis accompanying bilateral radicular findings, protecting the integrity of pars and facet joint on this side gains importance for stability and to control postoperative pains. According to the minimal invasive surgery's logic, unilateral laminotomy seems to be a best option in these cases. As a matter of fact, in our study, in the patient group that had been applied canal decompression from opposite side of the side where far lateral discectomy is applied, and thus had not been fractured during postoperative period because it had not been trimmed from pars interarticularis medial, protecting the facet joint, postoperative back and leg pains in 1st year were found less. In cases in which both far lateral discectomy was applied with median incision and bilateral canal decompression was carried out after laminotomy and medial facetectomy from the side of the disk, the risk of instability and postoperative back and leg pain in year 1 was observed more. This was found out during the postoperative controls of the patients in year 1 . The pars, which had weakened after pars interarticularis had been trimmed from interior and exterior, was observed to fracture in the postoperative period. Hence, in the dynamic graphs measured due to increasing back and leg pains in $57.1 \%$ of the patient group, more than half of the patients were confirmed radiologically to have pars interarticularis fracture. Cases with occurrence of instability who did not respond to conservative treatment were stabilized following surgery, and improvement was observed in back and leg pains of patients. In patients to whom canal decompression was carried out from the opposite side of far lateral discectomy, postoperative instability was not observed and another surgical intervention was not needed since both pars interarticularis and facet joint of the same side could be protected.

Based on our statistical data, there is no difference in early postoperative results of both group of patients and both groups have benefited from surgical intervention. However, since instability has occurred depending on pars interarticularis fracture by time, an increase has been observed in the 

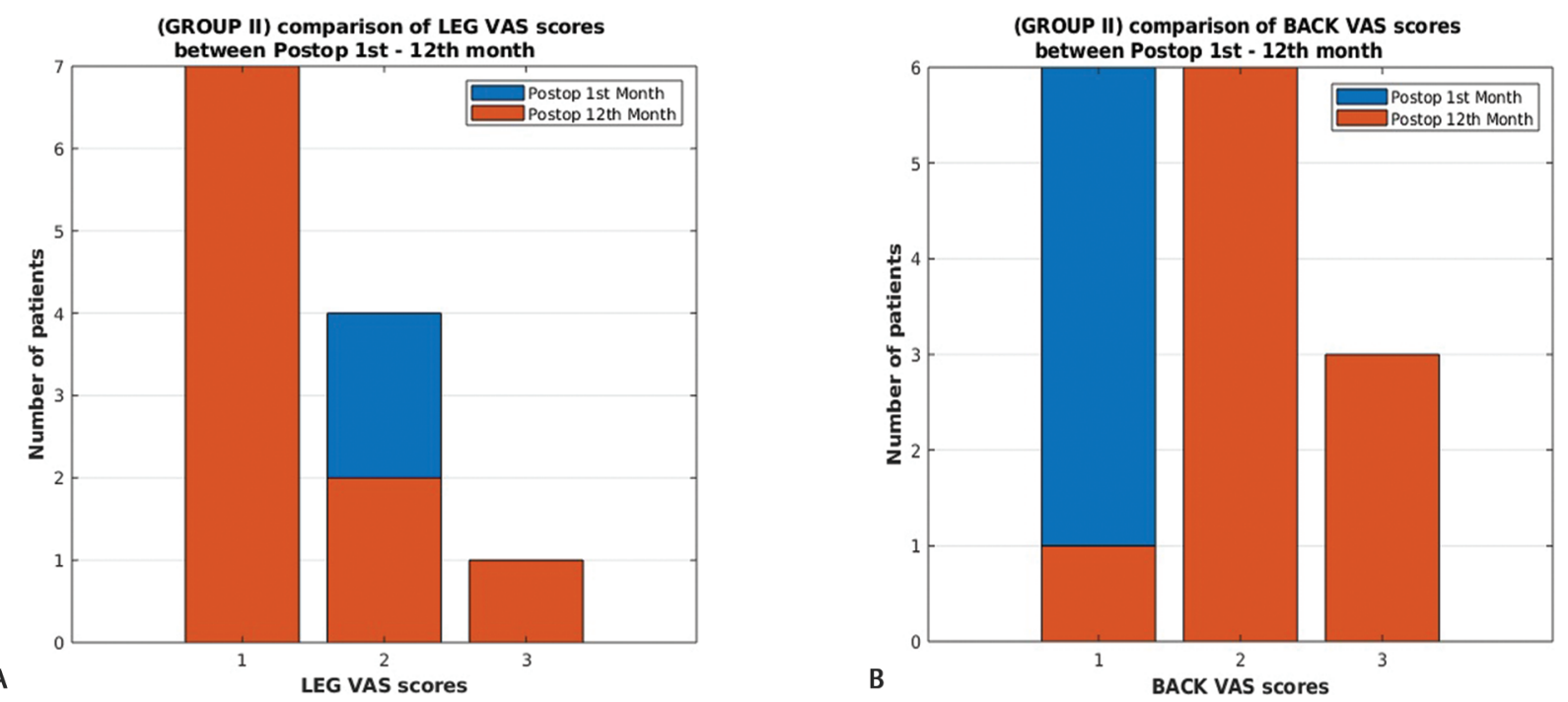

Fig. 3 (A) Comparison of leg Visual Analogue Scale (VAS) scores between postoperative 1st and 12th months for group 2. (B) Comparison of back VAS scores between postoperative 1st and 12th months for group 2.
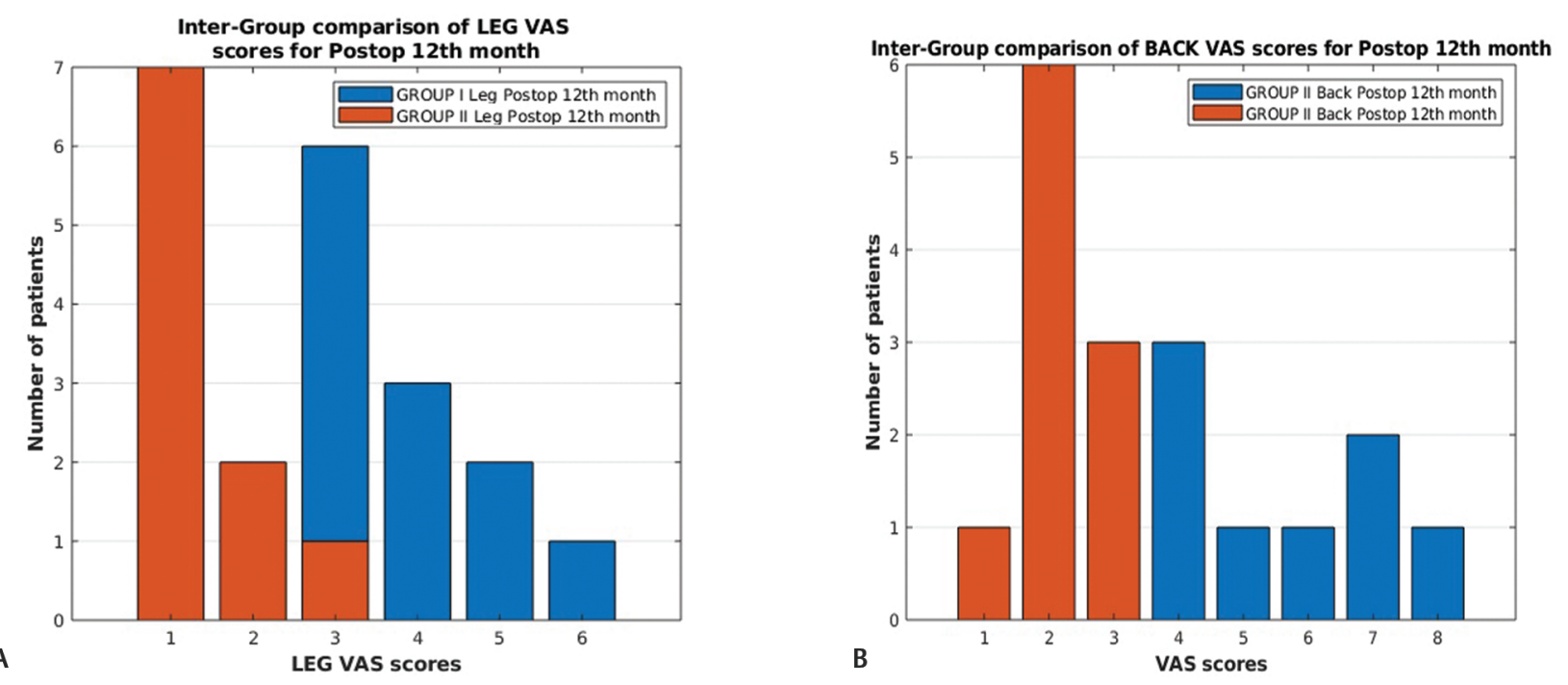

Fig. 4 (A) Intergroup comparison of leg Visual Analogue Scale (VAS) scores for postoperative 12th month. (B) Intergroup comparison of back VAS scores for postoperative 12 th month.

back and leg pains of most of the patients who have been through bilateral spinal canal decompression with unilateral approach from the side where far lateral disk herniation is located and median incision. We assume that our findings will be supported when the follow-up period and number of cases are increased in our study.

\section{Conclusion}

In the long term, we recommend this approach in cases with far lateral disk herniation and spinal stenosis since it decreases instability and hence the need for secondary surgery. The fact that two separate incisions such as median and paramedian are required to protect pars interarticularis and the surgical period is long can be considered as the limitations of the proposed technique.

\section{Conflict of Interest}

None declared.

\section{References}

1 Salame K, Lidar Z. Minimally invasive approach to far lateral lumbar disc herniation: technique and clinical results. Acta Neurochir (Wien) 2010;152(4):663-668

2 Hodges SD, Humphreys SC, Eck JC, Covington LA. The surgical treatment of far lateral L3-L4 and L4-L5 disc herniations. A modified technique and outcomes analysis of 25 patients. Spine 1999;24(12):1243-1246

3 Wiltse LL, Bateman JG, Hutchinson RH, Nelson WE. The paraspinal sacrospinalis-splitting approach to the lumbar spine. J Bone Joint Surg Am 1968;50(5):919-926

4 Getty CJM, Johnson JR, Kirwan EO, Sullivan MF. Partial undercutting facetectomy for bony entrapment of the lumbar nerve root. J Bone Joint Surg Br 1981;63-B(3):330-335 
5 Nakai O, Ookawa A, Yamaura I. Long-term roentgenographic and functional changes in patients who were treated with wide fenestration for central lumbar stenosis. J Bone Joint Surg Am 1991;73(8):1184-1191

6 Akar E, Somay H. Comparative morphometric analysis of congenital and acquired lumbar spinal stenosis. J Clin Neurosci 2019;68:256-261

7 Arnoldi CC, Brodsky AE, Cauchoix J, et al. Lumbar spinal stenosis and nerve root entrapment syndromes. Definition and classification. Clin Orthop Relat Res 1976;(115):4-5

8 Javid MJ, Hadar EJ. Long-term follow-up review of patients who underwent laminectomy for lumbar stenosis: a prospective study. J Neurosurg 1998;89(1):1-7

9 Mayer HM, List J, Korge A, Wiechert K. [Microsurgery of acquired degenerative lumbar spinal stenosis. Bilateral over-the-top decompression through unilateral approach] [in German]. Orthopade 2003;32(10):889-895

10 Jönsson B. Vertebral slipping after decompression for spinal stenosis. Acta Orthop Scand Suppl 1993;251:76-77

11 Thomé C, Zevgaridis D, Leheta $\mathrm{O}$, et al. Outcome after lessinvasive decompression of lumbar spinal stenosis: a randomized comparison of unilateral laminotomy, bilateral laminotomy, and laminectomy. J Neurosurg Spine 2005;3(2): 129-141

12 Rahman M, Summers LE, Richter B, Mimran RI, Jacob RP. Comparison of techniques for decompressive lumbar laminectomy: the minimally invasive versus the "classic" open approach. Minim Invasive Neurosurg 2008;51(2):100-105

13 Ogrenci A, Koban O, Yaman O, Yilmaz M, Dalbayrak S. Clinical comparison between patients operated for unilateral radiculopathy via a contralateral (facet-sparing) and ipsilateral side approach. Turk Neurosurg 2018;28(4):610-615

14 Choi WS, Oh CH, Ji GY, et al. Spinal canal morphology and clinical outcomes of microsurgical bilateral decompression via a unilateral approach for lumbar spinal canal stenosis. Eur Spine J 2014;23(5):991-998

15 Oertel MF, Ryang YM, Korinth MC, Gilsbach JM, Rohde V. Long-term results of microsurgical treatment of lumbar spinal stenosis by unilateral laminotomy for bilateral decompression. Neurosurgery 2006;59(6):1264-1269

16 O’Toole JE, Eichholz KM, Fessler RG. Minimally invasive far lateral microendoscopic discectomy for extraforaminal disc herniation at the lumbosacral junction: cadaveric dissection and technical case report. Spine J 2007;7(4):414-421

17 Al-Khawaja DO, Mahasneh T, Li JC. Surgical treatment of far lateral lumbar disc herniation: a safe and simple approach. J Spine Surg 2016;2(1):21-24

18 Ivanov AA, Faizan A, Ebraheim NA, Yeasting R, Goel VK. The effect of removing the lateral part of the pars interarticularis on stress distribution at the neural arch in lumbar foraminal microdecompression at L3-L4 and L4-L5: anatomic and finite element investigations. Spine 2007;32(22):2462-2466 